\title{
Multidrug resistance of uropathogenic Escherichia coli strains isolated from diabetic patients
}

\author{
Oana Mariana lonete ${ }^{1 *}$, Carmen Avrămescu' $^{1}$, Maria Bălăşoiu', Carmen Dobjanschi ${ }^{2}$ \\ From The 10th Edition of the Scientific Days of the National Institute for Infectious Diseases "Prof Dr Matei \\ Bals" \\ Bucharest, Romania. 15-17 October 2014
}

\section{Background}

Urinary tract infections (UTI) in diabetic patients are due to certain pathogenic microorganisms, the most common being Escherichia coli. There can also be selected multiple bacterial strains resistant to antibiotics. There are several risk factors predisposing to infection in these patients, especially if glycemic control is poor.

\section{Methods}

This study conducted for one year included patients with type 1 and 2 diabetes hospitalized in the clinic for diabetes, nutrition and metabolic diseases in the Emergency County Hospital of Craiova, with or without symptoms of UTI. To make a distinction between contamination and true infection is important which method is used for this purpose. We used the midstream urine collection, especially in females. From these samples collected we have determined germs involved in UTI and have tested resistance to antibiotics of Escherichia coli strains isolated.

\section{Results}

Analyzing the degree of multidrug resistance of Escherichia coli strains isolated from urine samples, related to ciprofloxacin resistance, we observed that of the 97 strains studied from diabetic patients hospitalized in the clinic for diabetes, nutrition and metabolic diseases, 11 strains showed different degrees of multidrug resistance representing a percentage of 11.34. Multidrug resistance includes strains resistant to 2 to 7 antibiotics. Among the 11 strains studied, 9 had intermediate susceptibility to 2 to 6 antibiotics.

\section{Conclusion}

The number of multidrug resistant Escherichia coli strains compared to ciprofloxacin resistance was relatively low. Inappropriate use of antibiotics creates multidrug resistance. Meropenem remains a reserve antibiotic for multidrug resistant Escherichia coli strains, because all tested strains were susceptible. Drug resistance surveillance must be done periodically and it can be informative for appropriate management of antimicrobial resistance and for adequate and effective treatment.

\section{Authors' details \\ ${ }^{1}$ University of Medicine and Pharmacy Craiova, Romania. ${ }^{2}$ Carol Davila University of Medicine and Pharmacy, Bucharest, Romania.}

Published: 15 October 2014

doi:10.1186/1471-2334-14-S7-P44

Cite this article as: lonete et al:: Multidrug resistance of uropathogenic Escherichia coli strains isolated from diabetic patients. BMC Infectious Diseases 2014 14(Suppl 7):P44.

Submit your next manuscript to BioMed Central and take full advantage of:

- Convenient online submission

- Thorough peer review

- No space constraints or color figure charges

- Immediate publication on acceptance

- Inclusion in PubMed, CAS, Scopus and Google Scholar

- Research which is freely available for redistribution 